\title{
INDUSTRIAL ECOLOGY AND LEGISLATION OF THE ECOLOGICAL APPROACH TO PRODUCTION IN THE COUNTRIES IN TRANSITION AND THE EU
}

\author{
Veljko Vuković, ${ }^{1}$ Mladen Ivić, ${ }^{2}$ Miljana Vuković ${ }^{3}$ \\ ${ }^{1.2}$ University for Business Engineering and Management, Banja Luka, Bosnia and Herzegovina \\ ${ }^{3}$ University of Novi Sad, Faculty of Technical Sciences, Serbia \\ ivic.mladen@gmail.com
}

\begin{abstract}
It is on the way of producing that how many resources and how much energy we would spend, how many harmful substances would appear in the environment, as well as how the life cycle of a product would be like depends. Through certain interventions in the production process we can have a favorable impact on all these parameters. By using higher quality materials we have a direct impact on quality and longer life cycle of the product, by using a better technology we reduce the consumption of energy and resources, by a better and more efficient design we have an impact on the energy consumption throughout life cycle of the product, and by all of the aforementioned things we contribute to less pollution and sustainability of our environment. Therefore, it is quite clear that today the industrial ecology is one of the most significant aspects of the production issues in the Republic of Srpska and the EU.
\end{abstract}

Key words: environmental protection, industrial ecology, eco-product, pollution, approach, tools, concepts, legislation, the EU.

\section{INTRODUCTION}

This paper provides an overview of the industrial production impact on polluting the environment, as well as of the way in which that impact can be reduced. The terms of sustainable development, social business and industrial ecology have been explained and through them the overview of the best concepts and tools by which we can reduce the pollution of industry and industrial product in the
Original Scientific Paper doi:10.5937/jouproman5-14312 environment and contribute to the sustainability of our planet is provided. This paper provides an overview of the European eco laws with regulative recommendations which are necessary to our industry for the sake of the product competitiveness and the very access to the market of the European Union. In this sense, the procedures which the industrial entities of the countries in transition, as well as of the Republic of Srpska should implement in order to follow the step of the eco-principles of the EU are hereby described. Therefore, this paper deals with the matter which can help in the process of verification and obtaining the socalled environmental permit for industrial enterprises, as well as obtaining the valid certificates for one's own eco product. In the further study in this paper the activities of state bodies, non-profit organizations and companies dealing with the environmental protection are described and the ecological approach of our processing industrial products and the impact of regulations on the business are analyzed. Based on the aforementioned, in this paper the effects of the enterprises which have harmonized their technological developments according to the eco-directives and by the product placement onto the European market have been presented. 


\section{GENERAL TERMS ON THE ENVIRONMENTAL ECOLOGY}

Ecology is a biological discipline which studies relations, structure and functioning of the nature in general, including the man, i.e. mankind as a specific component of the biological systems on the Earth. It deals with the relations of living beings and their environment, as well as the mutual relations of all organisms in the nature. The contemporary definition of ecology emphasizes that it is a science which studies the solutions realized by living beings, in different ways, as a result of the problems which were assigned to them by the environment and which they had to solve through their evolution in order to survive in those specific environments. To put it simply, ecology can be also defined as a science which studies mechanisms of survival of living beings on the planet Earth.

\section{INDUSTRIAL ECOLOGY}

The development of industrial ecology is an attempt to offer a new conceptual framework to understand the impact of industrial systems on the environment. That new framework serves for identification, and later on implementation of the strategies for reducing the impact of products and processes related to the industrial systems on the environment with the ultimate goal of the sustainable development. Industrial ecology is a science of physical, chemical and biological interconnections and interactions within and between the industrial and ecological systems. Some scientists consider that the industrial ecology includes identification and implementation of the strategies by means of which the industrial systems should be as similar as possible to the harmonious, sustainable, ecological ecosystems. The industrial system cannot be considered separately from the social community and the environment. In the literature 3 significant interconnected systems are most commonly perceived:

- Industrial system

- Social community

- Natural system (environment)

Between the industrial system and the environment there are ecological aspects, between the industrial system and the social community there are economic aspects, and between the social community and the environment there are human-ecological aspects. However, it is necessary to identify also the fourth aspect, considered by many to be the most complex one, the socialecological aspect which implies the following relations: the environment provides the resources which the social community inputs through operation into the industrial system which offers to the community the products and services which the social community uses and through them has an impact on the environment once again. In this regard, its significant role with a view to elements of the ecological risk also appears. The ecological risk represents probability of occurrences which provoke a hazard to people and the environment. The elements of the ecological risk include:

- Strategy of the economic development (of a region, community)

- State of the level of industrial development of certain regions

- Locations of industrial facilities

- Types of production (presence of toxic substances) 
- Competence and ecological education of people

- Measures of the preventive environmental protection

- Organizing the overall system of the ecological security.

For responsible doing business it is very important to perceive clearly the problems which have an impact on the state of the environment. In that regard, the proper management of the materials and energy consumption is of great importance. Assuming that, the assignment which the industrial ecology has set to itself is primarily the change of the linear nature of the industrial system by which from raw materials we get products, byproducts and waste into the cyclic system in which waste becomes raw material input for some other process which leads to its increased efficiency and reduced burden on natural resources. In this regard, 3 production types which can be applied to the term industrial ecology are known.

System type $\mathbf{I}$ is represented as a linear process in which the material and energy are inputted into one side of the system and outputted at the other side in the form of a product, byproduct and waste. Since waste and byproducts are not recycled, this system depends on the constant supply of raw materials and energy. However, as natural resources are not infinite, and the environment can receive only a limited amount of waste, this system is absolutely unsustainable, and still it is applied quite a lot in the countries of the region, as well as in the Republic of Srpska.

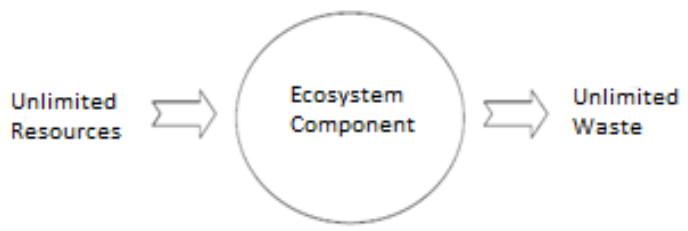

Fig.1. Production system type I

System type II represents most of the today's industrial systems of the developed countries and the countries in transition. A part of waste is recycled and taken back into production, and another part of it is deposited in the environment. This system represents a quasi-cyclic flow of materials and it is more efficient than type $\mathbf{I}$. However, it is not sustainable for a long period because the flow of materials occurs in a single direction.

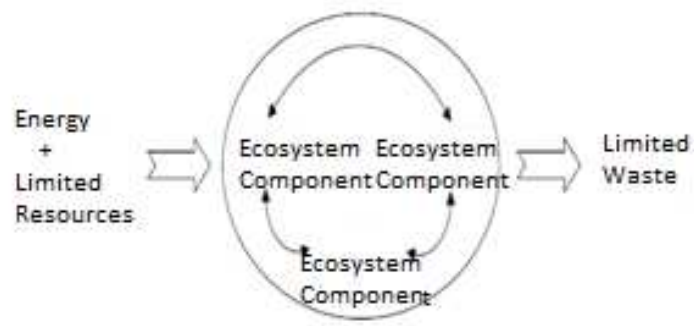

Fig.2. Production system type II

System type III represents a dynamic balance of ecological systems where the energy and waste are constantly recycled and reused by other organisms and processes in the system. It is a highly integrated, closed system. In the completely closed industrial system only the sun energy would come from the outside while all byproducts would be constantly recycled within the system. Production system type III represents a sustainable state and an ideal objective of the industrial ecology. 
Of course, in practice this system is not possible because of the degradation of substances (the finite number of recycling with keeping the basic qualities of materials). Likewise, a part of energy is irretrievably burnt during a process and it is impossible to take all the energy within the system back to the input. Therefore, this system also requires continuous energy supply.

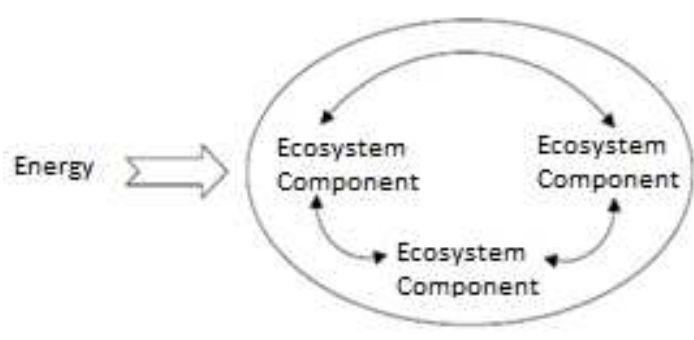

Fig.3. Production system type III

These three above stated ecological systems, which are recognized within the framework of the traditional biological ecology, are also very simply applicable in the framework of the industrial ecology if we replace the components of the ecosystem by the phases of production. The basic concept is to transform systems type I and II into system III.

\section{ECOLOGICAL APPROACH TO PRODUCTION}

Along with the production development, the problem of waste and its impact on the environment was also developing. In the beginning of the industrial production the environment seemed as though it was an infinite reservoir of waste and the impact of the waste on the state of that "reservoir" was not taken into account much. It used to be considered that the environment can absorb and degrade all substances which we deposit there, and furthermore regenerate them and restore their original state in some miraculous way. Today we are certainly aware that the situation is quite the opposite. For that purpose today the great efforts are being made and the principles and tools by which we tend to reduce the industry impact on the environment are being elaborated. According to the impact on the environment, today we differentiate 4 basic approaches to production:

1. Traditional approach represents the way in which we have treated the environment so far as an inexhaustible waste reservoir. That behavior has led to the current state of the environment and it is considered to be completely old-fashioned and undesirable. The practice includes:

- Disposal / dilution of waste/

- End of pipe - processing and waste disposal after it has already been generated.

2. Preventive approach represents a modern approach to the issue of the environment and waste. It recognizes the connection between the industry and the state of resources, the need to use them in a more efficient way and it tends to solve the waste problem at its source. The practice includes:

- Cleaner production with minimizing the waste

- Environmental management system (EMS)

- Production focused on using the available resources in as efficiently as possible.

\section{Production focused on the product}

tries to have an impact on the environment through as efficient and ecological design of the product as possible, and it takes into consideration its impact on the environment through its whole life cycle. 
The emissions of hazardous substances are observed from the moment of excavation of raw materials to waste disposal of the used product. Some of the methods used are:

- Eco-design

- Eco-efficiency

- LCA - life cycle assessment

- LCM - life cycle management.

4. Dematerialization perceives the product as a way by which some service is provided to the customer. If the focus is to provide that service as good as possible, it automatically leads to a better product design and a more efficient use of it through the use of materials, energy consumption and waste disposal.

The most obvious example of a conversion of these principles into an act can be seen in the car industry which represents one of the biggest polluters of the environment both in the production phase and in the usage phase. It is clear that the interventions in the production process and use of higher quality and recycled materials shall contribute considerably to increase the emission of hazardous substances into the environment, but if we pay more attention to the car as a product and the service which it provides to the customer, we can realize even greater improvement in terms of the impact on the environment. If in the designing phase we pay more attention to reducing fuel consumption, reducing emissions of harmful gases and to a longer product life cycle, and at the expense of some other purely cosmetic accessories (which demand additional energy and materials consumption for their production, and they needlessly raise the product price and its impact on the environment) while at the same time we raise the awareness of consumers about the product through the information system and providing nonmaterial services, we can really talk about eco-conscious production and consumption.

\section{TOOLS AND ECO CONCEPTS}

Along with development of the concept of the sustainable development and industrial ecology, it is necessary to develop the tools and concepts which shall help us achieve the final goal of the sustainable system. In the following chapters some of the most significant tools used today shall be presented.

\section{MIPS}

The concept of MIPS (Material Input per Unit of Service) was originally created in the 90-s of the last century in Germany. The MIPS is used to measure the eco-efficiency of a product or a service and it can be applied both in case of individual products and complex systems. The budget takes into account the quantity of materials needed for producing a product or a service. The smaller the material input per kilometer is, the more eco-efficient the car is. It is presented by the general formula as follows:

MIPS = MI / S = Material Input / Unit of Service $=$ Material Input per Unit of Service

In the MIPS calculations the whole product life cycle is taken into consideration. In that way the comparison of the resources consumption of different products which perform the same function is facilitated. In the event of examining an individual product, the MIPS budget reveals the extent of resources consumption during the life cycle and it helps to focus on the most significant phases of the cycle in order to reduce the environmental burden of the product. 
The eco-efficiency increases in case of reducing the quantity of materials needed for producing a product, i.e. reducing the MIPS values.

\subsection{Ecological footprint}

The ecological footprint is a measure of human demand in regard to the Earth's ecosystem. It compares the human demand with the Earth's ecological capacity to regenerate. The ecological footprint represents the quantity of the biologically productive area of land and sea needed for regeneration of the resources consumed by the human population and for absorption of the waste generated through that consumption. By using that assessment we can obtain the data on how much of the Earth's surface (or how many entire planets Earth) would be needed to sustain humanity with a certain lifestyle. According to the data from 2006 the overall ecological footprint of today's population of the Earth is estimated as 1.4 of the Earth. In other words, human communities consume the resources 1.4 times faster than the Earth can renew them. This index is calculated every year with postponement of three years how much is needed that the UN collects, processes and publishes the data. Though the ecological footprint has become a popular term, the methods of measurement vary. Most calculations are based on two facts:

- We can measure the quantity of the resources we use and the waste we generate

- Those measurements we turn into the equivalent of the useful surface of land and sea.

\subsection{Zero emission}

The concept of the zero emission represents a shift from the traditional industrial model which implies the existence of waste to the integrated system in which everything has its purpose. The zero emission promotes the industrial transformation through which the production systems should emulate the sustainable cycles the kind we find in the nature, and the society should minimize the burden imposed on natural resources through learning how to do more with what the environment provides. This concept provides for the use of all industrial inputs (material, energy, etc.) in the final products or the conversion into inputs with the additional value for other processes or industries. The waste elimination represents an ultimate solution of the problem of pollution which threatens to the ecosystems at the global, national and local level. Better yet, the complete use of raw materials in combination with the use of renewable sources means that the use of natural resources could be taken back at the sustainable level. From the historical point of view, the zero emission represents the next evolutionary phase in controlling and reducing the emission of harmful substances from the industrial sources of pollution:

- End of pipe - using technologies of the pollution control for processing the process waste

- Clearer production - redesigning the process and product in order to reduce the emissions of harmful substances at the source

- Zero emission - conversion and use of the process outputs as the inputs for other processes. 
It is quite clear that production and consumption are closely related processes. Therefore, when applying the zero emission one should take into consideration the whole social system within which the industrial activity occurs. Eventually, it should be emphasized that achieving the strict zero emission is not possible according to the laws of physics. There is no process which occurs with $100 \%$ of usability and losses such as the heat loss will always exist. The concept of the zero emission does not claim that all emissions from some industrial process shall be at the zero level.

\subsection{Development of the sustainable technology}

Considering the state of natural resources in the world, as well as the constant population growth, it is clear that there must be done some changes in the way in which people live and work. One of the main reasons for that is the fact that some of the resources we are using today are restricted. The second reason, maybe the more significant one, is that the way in which we meet the needs today shall not be enough for even bigger population which is predicted to happen at the end of the century. The development of sustainable technologies means finding new solutions for the lifestyle changes which are appropriate for the current and future generations. The development of the process in the future will be based on the concept of development for the environment of the sustainable chemical and physical operations. It means reducing the environment pollution, saving the energy and raw materials what should be provided in all phases of the process development, in every segment of the production chain. Sustainable technologies use less energy and fewer restricted resources, they do not pollute the environment directly and indirectly and can be reused or recycled at the end of the life cycle. Some of the sustainable technologies being researched and improved today are application of bio-fuels, the sun energy, development of the sustainable agriculture and waste management through reusing and recycling. The technology of producing the bio-fuels is based on the fuel production from agricultural products such as corn, rapeseed and sugarcane. This technology has its followers and opponents since some scientists claim that essentially it is not sustainable because for the production of large quantities of fuel we need large quantities of soil which in that case cannot be used for nutrition of the population. The sustainable technology deals with the fuel problem with the initiative to use electric vehicles. This technology deals with producing the vehicles which would be charged by electricity instead of traditional fuels, as the electricity can be produced in a sustainable way through the solar or wind energy. For that purpose the solar, wind and water energy can be used. The solar technology, as its name suggests, uses the solar energy to produce electricity and it is very widespread since the sun is perceived as an inexhaustible source of energy. In addition to these main areas the sustainable technologies are nowadays being applied in all fields of human activity, and particularly in the construction, urban planning, chemical industry, as well as in the agriculture and livestock breeding. 


\subsection{Cleaner production}

Cleaner production is continuous application of the comprehensive preventive strategy of the environmental protection on production processes, products and services in order to increase efficiency and reduce the risk for people and the environment. In the production process the cleaner production includes more efficient usage of raw materials and energy, preventing the occurrence of toxic and hazardous materials, as well as reducing all emissions and waste at the source. The strategy of cleaner production is also focused on the overall reduction of the impact during the whole life cycle of products and services, from their designing to their use and final disposal. Since the application of cleaner production in most cases does not involve the changes of tools and plants, but only of the approach and skills of using materials and designing the product, it is clear that through it a fast economic profit can be achieved even without any significant financial investments. In that way two seemingly contrary terms, the environmental protection and profit are connected through cleaner production. The very process of cleaner production can be most easily explained by comparing it to the traditional approach to waste, so called end of pipe technology which is focused on waste and byproducts derived at the end of a process. That kind of waste requires processing (incineration, water purification, etc.).

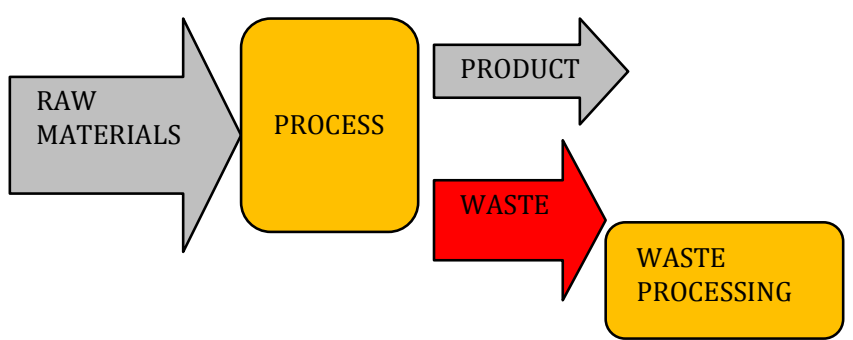

Fig.4. Traditional production process
Unlike that approach which treats the consequences, the cleaner production deals with the causes of the problem. It raises a question where the waste comes from, why it occurs and how to reduce it at its source. By interventions in the production process, use of high-quality materials and better product design one can achieve significant savings of materials and energy and reduce emissions of harmful substances in the environment. Cleaner production tends to avoid waste generation since less waste means better used materials and less environmental pollution which automatically increases the productivity and profit.

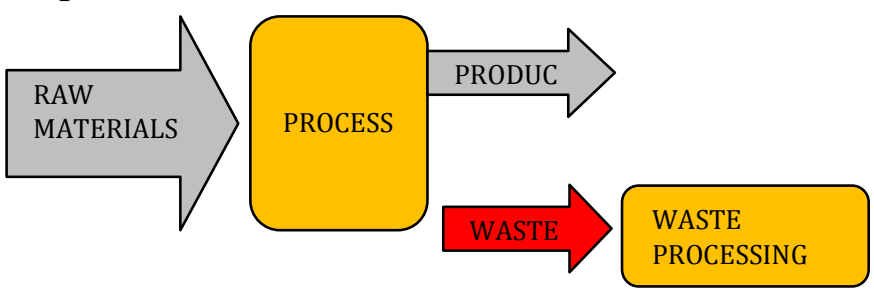

Fig.5. Production process after cleaner production

All the above stated things provide clear reasons for implementing the cleaner production. Its principles are useful to everyone, be it big companies or smallscale businesses because responsible behavior toward the environment and resources is nowadays everyone's concern. Considering the state and quantities of natural resources and their price increase, no one should permit the losses of materials through waste.

\subsection{Eco-efficiency}

The term "eco-efficiency" was first used in 1992 in a publication of the World Business Council for Sustainable Development (WBCSD16) called "Changing Course". 
It is based on the concept of producing larger quantities of products and services by using smaller quantities of resources and therefore with generating less waste and pollution. According to the definition of the WBCSD, the eco-efficiency is achieved by providing products and services which meet human needs at a competitive price, with progressive reduction of the impact which those products have on the environment and natural resources through their whole life cycle, at least to the level of the estimated Earth's natural capacity. In that the ecoefficiency is similar to the concepts so far described in this paper, but with the focus on as good usability of input parameters as possible. Literally, it is "getting more from less". According to the WBCSD, the critical aspects of the eco-efficiency are:

- Reducing the material intensity of products or services

- Reduced spreading of toxic materials

- Improving the material recycling

- Maximizing the use of renewable resources

- Increasing the durability of products

- Increasing the number and quality of the services provided by the product.

Theoretically, the eco-efficiency can be defined as a relation of the ecological gain and production expenses:

$$
\mathrm{EE}=\frac{\text { Ecological gain }}{\text { Expanses }\left(\frac{E C U}{\mathrm{~kg}}\right)}
$$

$\mathrm{ECU}=$ Economic Unit (any economic unit)

The ecological gain can be defined as any value which has the ecological significance, e.g. reducing the quantity of harmful substances deposited in the environment, etc.

\subsection{Eco-design}

The eco-design is one more tool of the ecological approach to production aimed at a product in the phase of designing. The basic concept is to minimize the product impact on the environment throughout the entire life cycle, which consists of production, packaging, transport and disposal after use, by using intelligent design solutions already in the preparatory phase of production. The eco-design is carried out through an assessment, identification, prioritization, as well as solving the problems through the changes in the product design. Those solutions can be related to using different materials, reducing the energy consumption during the use or reducing the product weight. The point of the eco-design is through these changes to retain or improve the quality of the service provided by a product which is why the incorporation of the ecological principles in the product design is of the crucial significance for achieving the sustainable development. The principles of the eco-design are present in all fields of human activity. They are applied in the mechanical engineering, architecture, urbanism, graphic design, horticulture, etc. Regardless of the field of activity, there are 10 golden rules of the eco-design which designers should comply with or at least find the best compromise among them:

1. Avoid toxic substances, i.e. if their use is inevitable, ensure their safe disposal. 
2. Minimize the consumption of energy and resources in the phases of production and transport.

3. Minimize the consumption of energy and resources in the usage phase, particularly for the products which use a lot of energy during the use.

4. Promote repair and upgrading of products, particularly of the significant components of a system.

5. Promote a long working life of products, particularly of the products which have a significant impact on the environment in the phase of their disposal at the end of their life cycle.

6. Use the design solutions and highquality materials in order to reduce the product weight without an impact on the quality of the provision of services.

7. Use better materials and surface treatments in order to protect products from the impacts of dirt, corrosion and wear.

8. Facilitate upgrading, repair or disassembly (because of recycling) through accessibility of components, labeling, aggregate structures, manuals, etc.

9. Promote upgrading, repair and recycling by using fewer, simple or recycled materials, but neither blended ones nor alloys.

10. Use as few components as possible, and for joining use standard fittings.

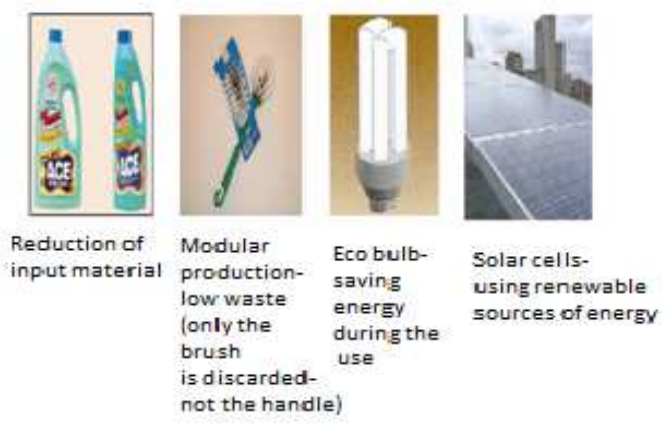

Fig.6. Examples of a successful eco-design

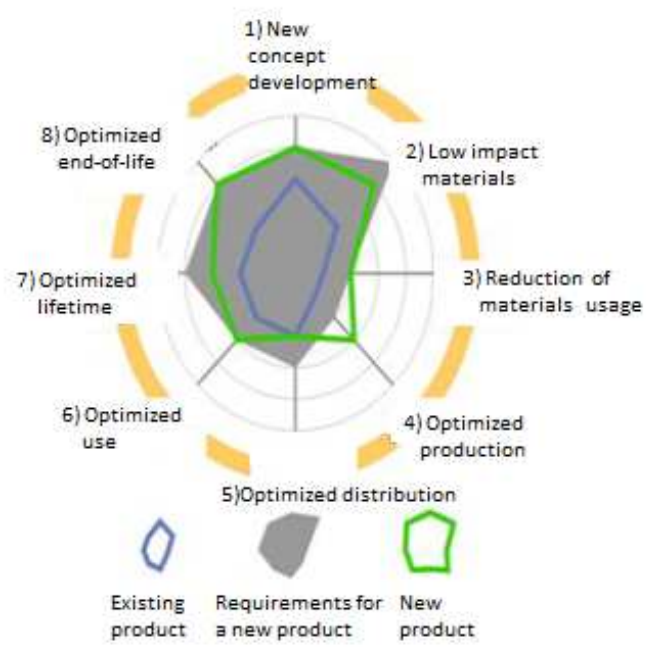

Fig.7. An example of graphic tracking of the eco-design performance

\section{APPLICATION OF STANDARDS FOR ECO- PRODUCTS, ISO STANDARDS}

The International Organization for Standardization (ISO) has issued a set of standards ISO 14000 for the purpose of helping economic entities worldwide with managing the ecological demands and ensuring that their ecological policies and practice meet their mission and goals. ISO 14000 is a voluntary standard dealing with introducing environmental management systems into companies through defining the requirements and guidelines for its development. 
It is a total of 21 standards which are related to various ecological issues such as an assessment of the impact on the environment, ecological labeling, the product life cycle, analysis, communication and environmental audit. The basis of the whole group is the ISO 14001 standard which provides a framework for a strategic approach to the environmental policy, plans and activities of an organization. At the same time it is the only standard according to which companies can be certified by the foreign certification bodies. It provides general requirements for establishing the environmental management system, and not the precise values because it is intended for wide use in various branches of human activity where determining the exact ecological impact would be pointless. The companies which introduce the ISO 14000 have to define their goals on their own, and the standard helps them achieve those goals and measure the performance. It literally means that two companies can have different measures and standards of the ecological efficiency, and still both of them can meet the requirements of the ISO 14001 standard. Therefore, it can be applied in a wide range of activities, but the companies certified for the ISO 14001 are obliged to comply with the valid ecological registrations and regulations, as well as to comply with the duty of continuous advancement for which the environmental management system provides the framework. The environmental management system which meets the requirements of the ISO 14001enables a firm of any size to:

- Identify and control the impact which its activities, products and services have on the environment.

- Improve continuously its environmental impact.
- Implement a systemic approach to setting the goals with a view to the environmental protection,

Achieve the set goals and prove it.

- Reduce the energy and materials consumption, as well as the waste disposal expenses.

- Ensure the compliance with the legislation in terms of the environmental protection.

- Improve the company image among consumers, investors and other stakeholders.

- Obtain more easily authorizations and permits from the local and state authorities.

\subsection{Ecological ISO standards}

- ISO $14001 \quad$ Environmental management systems (specification with guidance for use).

- ISO 14004 Environmental management systems (general guidelines on principles, systems and procedures).

- ISO 14010 Guidelines for environmental auditing (general principles).

- ISO 14011 Guidelines for environmental auditing (procedures of auditing, auditing the environmental management system).

- ISO 14012 Guidelines for environmental auditing (qualification criteria for environmental auditors). 


\section{LEGISLATION OF THE EUROPEAN UNION}

There are three basic types of the EU regulations: regulations, directives and decisions.

- Regulations are similar to state laws; the only difference is that they are applicable in all the Member States of the EU.

- Directives set the general rules which are transposed into the state legislation of the individual Member States according to their own requirements.

- Decisions only deal with precisely defined issues and specifically stated persons or organizations.

The field of the environmental protection is regulated by directives. Through them the European Commission provides the guidelines for elaborating the state laws by which individual directives or sets of directives are transposed into the legislation of an individual Member State. Complying with the directives is also a duty of the countries which are candidates for the membership of the European Union.

\section{CONCLUSION}

In this scientific paper the impact of industry on the environment and various tools and technologies by which we are trying to reduce that impact are shown, and among them the role of legislation in the environmental protection is particularly prominent. Considering that currently our country is in a particular situation when beside all the burden of the economic crisis, it has to find a way into the European integrations, a great part of this paper and reflections is focused on it. The European Union market is clear about the issues of the legislation in the environmental field being today one of the most important activities which have to be implemented and complied with pursuant to their procedures. Therefore, the countries in transition, including the Republic of Srpska must have the common position of all business industrial entities and associations that compliance of the industry and products with the eco-laws is indispensable for the purpose of making one's own product competitive, and thus providing the survival of one's own industry and products, and therefore, the state has to involve timely with its legal procedures, so the process of verification of the eco-industrial enterprises and products can be already activated. All this imposes an indispensable need that the legislator initiates organizing the specialist activities by which the important things in new duties of the production entities would be emphasized through holding various seminars and similar activities which would be implemented by the competent ministries and their specialist services.

\section{References}

[1] Jovanović L., (2002). "Zaštita atmosferskog vazduha (iskustvo Ruske Federacije) ",XXX savetovanje sa međunarodnim učešćem " ZAŠTITA VAZDUHA", Beograd.

[2] Biočanin R., (2003). "Protection of the human enviroment in case chemical accident", II regional Simposium "CHEMISTRY AND THE ENVIRONMENT" Zbornici radova sa naučno-stručnih skupova "ZAŠTITA VAZDUHA"-Beograd, Majski susreti zdravstvenih radnika Srbije-Zlatibor, Kruševac, 18-22. 
(JPMNT) Journal of Process Management - New Technologies, International

Vol. 5, No 3, 2017.

[3] Naučno-stručni časopisi " EKOLOGIKA ", "ZAŠTITA U PRAKSI", "BILTENABHO".

[4] Ilić M., "Naučno-nastavni materijali o upravljanju otpadom”, Tehnološki fakultet Univerziteta u Beogradu

[5] Krook, J., Svensson, N., Eklund, M., (2012). Landfill mining: A critical review of two decades of research. Waste Management 32.

[6] Randers, J., 2052, (2014). Globalna prognoza za sljedećih četrdeset godina, Mate d.o.o. Neum.
[7] NKEU- Nacionalni konvent o evropskoj uniji, Upravljanje otpadom i lokalni planoviDostupno:http://emins.org/sr/akti vnosti/projekti/reciklarnica/ 2011.

[8] http://www.iso.org/iso

[9] http://www.higherlevel.nl/forum/attach ments/10_goldenrules_in_ecodesign.pdf

[10] http://www.epa.gov/ 